\title{
MODELLING ANTHROPOGENIC EFFECT OF A TIDAL BASIN EVOLUTION
}

\author{
Pushpa Dissanayake ${ }^{1}$, Andreas Wurpts ${ }^{1}$, Marco Miani ${ }^{1}$ and Heiko Knaack ${ }^{1}$
}

\begin{abstract}
A numerical approach was undertaken to investigate an anthropogenic effect (i.e., construction of a peninsula in 1984) on the tidal basin evolution of the Ley Bay in the East Frisian Wadden Sea. Coupled hydro-morphodynamic model runs span from 1975 to 1990 applying both tidal and wave boundary forcings with a multiple-sediment bed. The offshore tidal force was transformed to the study area applying a cascade modeling approach while a highly schematised wave climate was adopted in this simulation. Two bathymetries (i.e., 1975 and 1990) were available for this study and therefore the peninsula was implemented based on the 1984 predicted bed. Resulting morphodynamic evolution indicates that the deeper areas (channels) are well reproduced by the model rather than the shallow areas (inter-tidal areas). In addition to the peninsula construction, the human interference by dredging and dumping appears to have influenced the Ley Bay evolution. Due to the lack of data availability, such information was not incorporated in this study. Comparisons of predicted and measured 1990 topographies in terms of qualitative and quantitative parameters show that the predicted bathymetry sufficiently resembles with the data. Application of a highly schematised wave climate affects on the bed evolution. Further investigation on the wave schematization could help to optimize the model prediction. On-going work uses this model set-up in order to forecast the Ley Bay evolution under future sea level rise scenarios.
\end{abstract}

Keywords: anthropogenic effect; morphological evolution; wave schematization; Ley Bay

\section{INTRODUCTION}

\section{Objective}

Anthropogenic effects such as diking, land reclamation, peat-cutting and damming of channels since the Middle Ages had a great influence on the present-day morphology of the Wadden Sea tidal basin systems. Further, reinforcing of existing dunes to serve as dikes, construction of jetties and closing of tidal basins (e.g., Zuider Sea (Thijsse 1972; Elias et al. 2003)) had major impacts on the Wadden Sea evolution. Eastern part of the Wadden Sea (i.e., East Frisian Wadden Sea) showed drastic changes of bed evolution due to these effects. Numerous examples are found on the Lower Saxony coast, e.g., Ley Bay, Harle Bay, Jade Bay etc (Homeier et al. 2010). Present analysis focuses on the bed evolution of Ley Bay due to construction of the 'Leyhörn' peninsula.

The Leyhörn peninsula has been constructed in 1984 to enable a number of functions (see Study area). Efficiency of these functions is directly related to the morphological set-up of the Ley Bay area. In turn, the Leyhörn interrupts to the existing system and therefore strong morphological changes can be expected in the bay. As such, a better insight of the possible bed changes of this area is of utmost importance to effective and efficient planning and management strategies. The overarching aim of this study is to forecast the bed evolution of the Ley Bay due to future sea level rise and climate change scenarios. In the present study, a morphological model is developed to hindcast the bed evolution from 1975 to 1990 considering the effect of the Leyhörn peninsula and both tidal and wave boundary forcings. Hindcasting of this area applying tidal boundary forcing only and different bed sediment compositions has been discussed in Dissanayake et al (2012a).

\section{Study area}

The Ley Bay is a part of the Oster-Ems basin which is located between Borkum (west) and Juist (east) barrier islands in the East Frisian Wadden Sea (see Fig. 1). This bay is characterised by a hierarchy of tidal gullies and tributaries of the adjacent tidal inlet. Large part of the basin area consists of intertidal flats and extended supratidal salt marshes with unique fauna and flora. This area has demanded human intervention in order to mitigate a number of coastal zone management issues:

- Safety of the coastal area against storm surges.

- Conservation of the Ley Bay as an unique ecological area.

- Establishing of inland drainage mainly by free-flow due to hydraulic gradient.

- Navigational access without maintenance dredging.

- Conservation of the traditional functions of the adjacent fishing harbour (i.e., Greetsiel, see Fig 1).

\footnotetext{
${ }^{1}$ Coastal Engineering Section, Coastal Research Station, An der Muehle 5, Norderney, Lower Saxony, D-26548, Germany
} 
Several strategies were formulated in order to address these management issues, of which the plan for enclosing of the Ley Bay area became more urgent because the existing dikes could not meet the safety requirements (Niemeyer 1984). However, this option resulted in a controversial public discussion with respect to the economic and ecological implications (Hartung 1983). Therefore, the State Government of Lower Saxony explored another solution based on the newly established social priorities and the traditional coastal zone management strategies in the Wadden Sea area. As an alternative, the Leyhörn peninsula was constructed in 1984 to meet the latter mentioned functionalities.

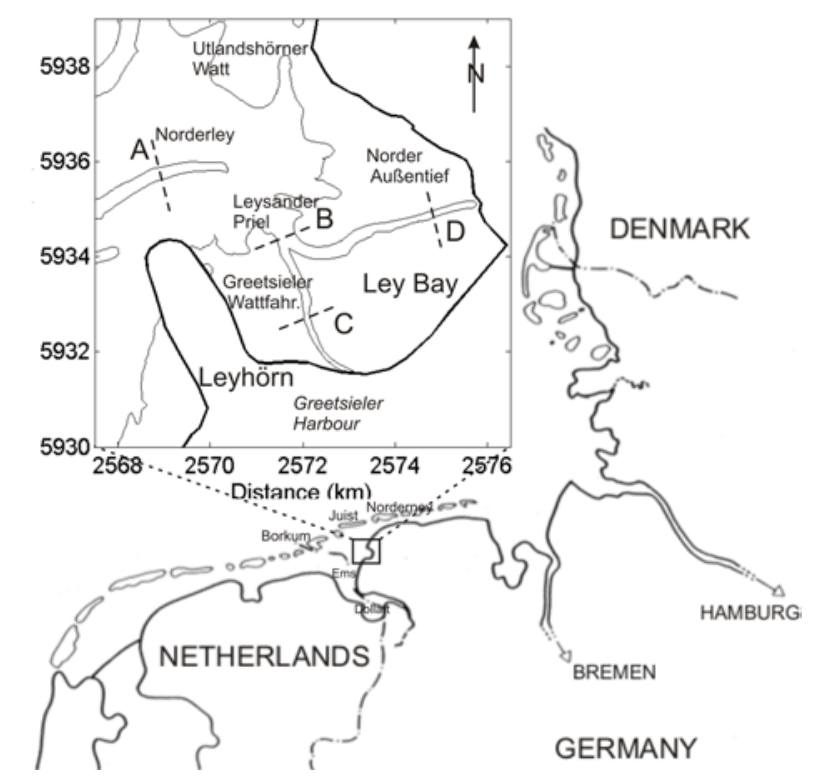

Figure 1. Location of the Ley Bay area in the East Frisian Wadden Sea

\section{MODEL IMPLEMENTATION}

\section{Approach}

Approach undertakes the depth-averaged version (2DH) of the Delft3D model suite to investigate the bed evolution in the Ley Bay area during 15 year period (from 1975 to 1990). This model solves the unsteady shallow water equations via the Alternating Direction Implicit (ADI) method to compute the hydrodynamics. Sediment transport is estimated based on the computed hydrodynamics and the user defined transport formula. Finally, bed evolution is obtained applying the online-morphology technique (i.e., MORFAC approach). The system of equations consists of the horizontal momentum equations, the continuity equation, a turbulence closure model and the transport equations. The application of these equations in Delft3D is described in detail by Lesser et al (2004) and is hence not reproduced here.

In this study, the model is simulated applying both tidal and wave boundary forcings. The tidal boundary is generated by means of a nested model approach while a highly schematised wave climate is adopted based on statistical wave data from 1975 to 1990. An initially distributed bed sediment composition which consists of three sediment fractions is used following the study of Dissanayake et al (2012a). The model runs are split in two stages considering the fact that the peninsula has been constructed in 1984. The first stage extends from 1975 to 1984. The peninsula construction is then manually implemented based on the model predicted 1984 topography and then run is continued up to 1990 in the second stage. Resulting bed evolution is compared in qualitative and quantitative sense with the 1990 measured data.

\section{Model bathymetry and grid}

Model area covers the entire Oster-Ems basin and uses the 1975 bed as the initial model bed (see Fig. 2a, outline indicates proposed peninsula). Resulting bed evolution is analysed based on the Ley Bay area only (see Fig. 2b). Two measured bathymetries, 1) 1975 and 2) 1990 of the Oster-Ems basin are used within the investigation (see Fig. 2). Averaged depth of the Ley Bay area (on 1975 bed) is about $+0.5 \mathrm{~m}$ MSL implying that tidal flats and salt marshes enclose a large part of the bay area. On the 1975 
bathymetry, there is a well-pronounced channel system in the Ley Bay area (see number 2, 3 and 4 in Fig. 2a). Leysander Priel (2 in Fig. 2a) is branched into two channels, namely Greetsieler Wattfahrwasser (3 in Fig. 2a) and Norder Außentief (4 in Fig. 2a). The Greetsieler channel provides the navigational access to the Greetsieler harbour while the Norder channel is mainly used to inland drainage in terms of pumping. The 1990 bathymetry shows the Leyhörn peninsula (length 3.5 km and width 1.5 km) whereas the access channel is not yet found because it has been implemented in 1991 (Knaack and Niemeyer 2001). The Ley Bay area shows strong sedimentation which results in shallowing Greetsieler and Norder channels (Fig. 2b). However, Leysander Priel appears to be deepened in comparison to the 1975 bathymetry. This is an indication of intensified current patterns at the entrance of the bay due to the presence of the peninsula.

a. Bathymetry - 1975

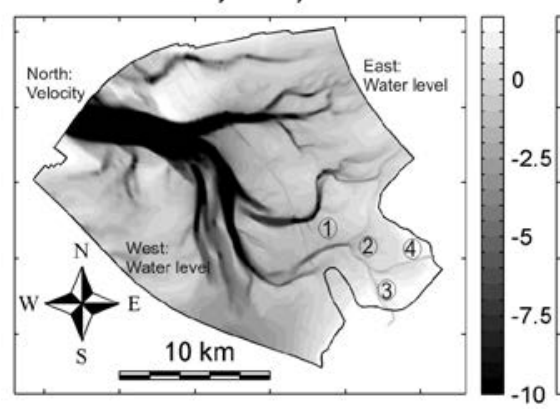

b. Bathymetry - 1990

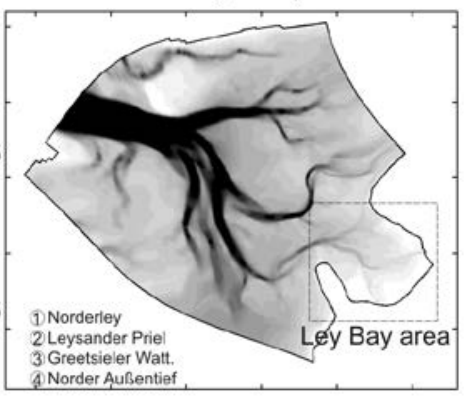

c. Model grid

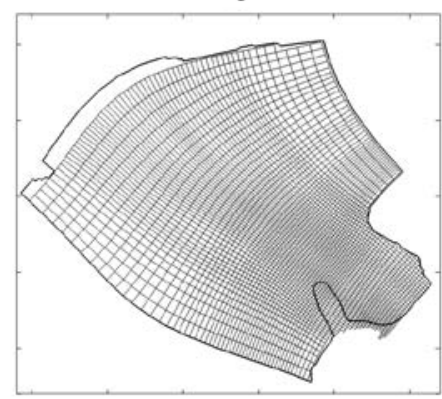

Figure 2. Measured bathymetries of the model area (Oster-Ems basin), 1975 bed with the layout of Leyhörn peninsula (a), 1990 bed with Ley Bay analysis area (b) and Model grid (every other 5th grid shown) (c)

Fig. 2c shows the model grid enclosing the Oster-Ems basin. Averaged grid size is about $200 \mathrm{~m} \times 200$ m. However, the Ley Bay area $(\sim 5.0 \mathrm{~km} \times 5.0 \mathrm{~km})$ has a high resolution $(\sim 20 \mathrm{~m} \times 20 \mathrm{~m})$ in order to resolve the bay channel pattern sufficiently.

\section{Tidal boundary}

The model area (i.e., Oster-Ems basin) has three open boundaries viz. north, east and west (see Fig. 2a). The north boundary is located at the inlet gorge and the east and west boundaries are in the Wadden Sea side opposite to the Norderney tidal basin and the Ems estuary respectively. Boundary forcings were estimated via the nested modelling approach in order to transfer the offshore (North Sea) hydrodynamic characteristics up to the Oster-Ems model boundaries (Wadden Sea). Model nesting was applied under two phases, 1) Continental shelf model to Coastal model, 2) Coastal model to Oster-Ems model. Initially, the continental shelf model (i.e., model enclosing the North Sea and British Isles up to the north Atlantic shelf, see Verboom et al. 1992) was run applying the astronomical constituents and then the water level elevations were extracted at the boundaries of the coastal model. Subsequently, the coastal model (see Knaack et al. 2003) was run to get the boundary forcings of the Oster-Ems model. Preliminary results indicated that applying three water level boundaries of the Oster-Ems model (at north, east and west), developed unrealistic velocity patterns. Therefore, flow velocity is applied for the northern boundary while the lateral two boundaries (i.e., east and west) use water levels.

\section{Wave and wind boundary}

The present analysis uses wave and wind climate from 1975 to 1990 at a location of about 17 m depth in front of the Norderney island. It is emphasized that applying a schematised wave/wind climate is unavoidable because the computational cost of the coupled approach which is used here does not allow multiple long-term model runs. As has been discussed in Dissanayake (2011), two reduction criteria are employed in this analysis.

- Wave conditions occurring less than $0.01 \%$ probability are neglected.

Apparently, such probability is associated with the extreme wave conditions. Therefore, this criterion removes the extreme waves from the analysis assuming the fact that effect of extreme waves on the long-term bed evolution is negligible. In other words, under normal wave conditions (i.e., calm periods), extreme bed level changes are reshaped.

- $\quad$ Relative contribution of each wave condition to the overall bed level change of the wave climate. In this criterion, wave conditions are schematised applying an iteration technique to remove those wave conditions which deliver the least contribution to the overall bed level change. 
Initially, scatter-diagrams are developed for the wave climate (probability of occurrence, significant wave height, mean wave period and direction) and wind climate (wind speed and direction) with the same wave height and directional classes. Therefore, each probability of occurrence has corresponding wave characteristics (height, period and direction) and wind characteristics (speed and direction). Following the first criterion, these six diagrams are used to define the wave conditions in which the probability of occurrence is higher than $0.01 \%$ and then their respective wind conditions also. Thus, the wave (wind) climate is schematised to 73 conditions after neglecting 14 conditions $(<0.01 \%$ probability). Accordingly, total probability of occurrence is reduced to 99.94 .

Remaining 73 conditions are further filtered under the second criterion. A short-term (e.g., a two-week morphological period) morphological models were separately run for each wave condition and the resulting erosion/sedimentation patterns are estimated. These patterns and their respective probability of occurrence (i.e., after adjusting the total probability of occurrence to 100) are used in the iteration procedure.

The iteration technique initially determines the overall bed level change of the wave climate by taking into account all individual patterns which resulted in applying each wave condition. Then, at each iteration step, one wave condition is removed based on the fact that it has the least contribution to the overall bed level change. The iteration steps continue until one wave condition is left. At each step, similarity of the bed level change of the reduced number of wave conditions and the overall wave climate can be observed with the resulting statistical parameters; correlation coefficient $\left(\mathrm{R}^{2}\right)$, Root Mean Square error (RMS), bias, covariance etc. Therefore, the user is able to determine the required number of wave conditions based on the variations of these statistical parameters.

Fig. 3 shows the RMS error (a) and the $R^{2}$ (b) variations in the present analysis with the 73 wave conditions. The RMS error is gradually increasing while the correlation coefficient is decreasing as one wave condition is removed at each step. In the case of the RMS error, remaining 4 wave conditions show lower value compared to that of the 5 wave conditions. The $\mathrm{R}^{2}$ indicates trivial changes up to the last 4 wave conditions. Then, there is a considerable step between 4 wave conditions and 3 wave conditions. Therefore, $\mathrm{R}^{2}$ also recommends selecting the 4 wave conditions. However, both parameters show selecting the last 8 wave condition leading to lower and higher values in the RMS error and the $\mathrm{R}^{2}$ respectively.
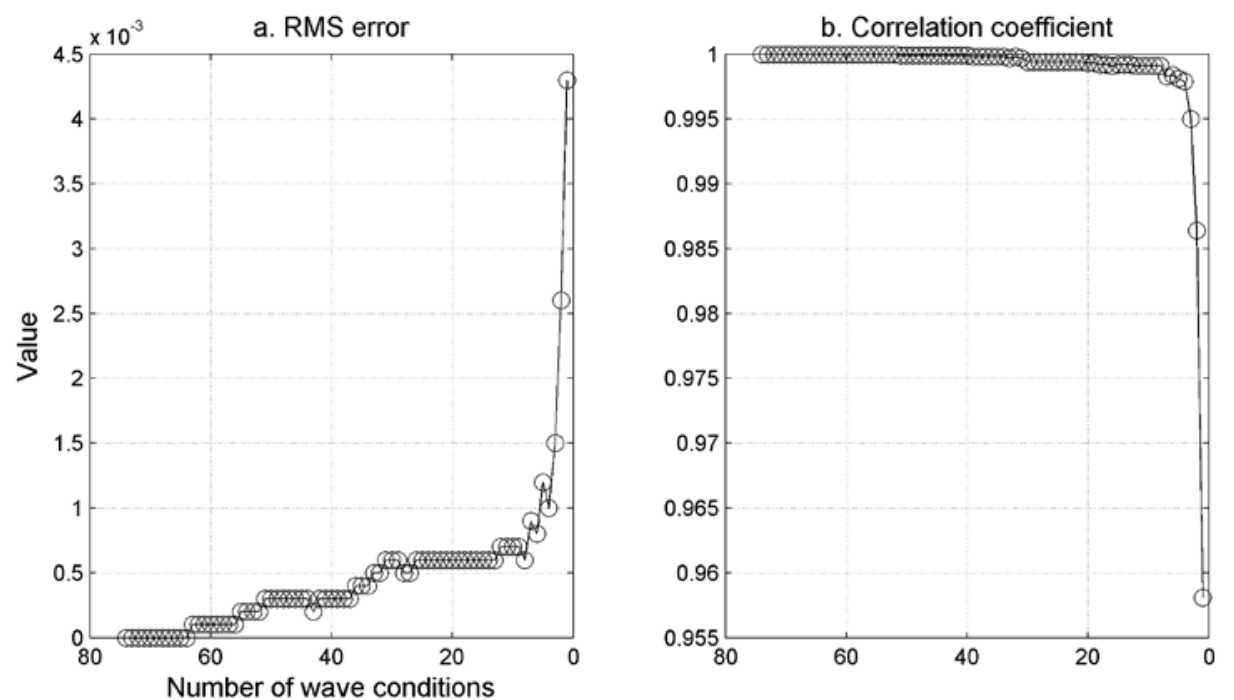

Figure 3. Variation of RMS error and Correlation coefficient at each iteration step, RMS error (a) and Correlation coefficient (b).

Resulting erosion/sedimentation patterns of the wave climate, 8 wave conditions and 4 wave conditions are compared together in order to further analyse the observations (see Fig. 4). The erosion/sedimentation patterns in all applications are found only along the channels because the bay consists of large inter-tidal areas. Predicted patterns in the wave climate and the 8 wave conditions are almost similar. A marginal difference is apparent of these patterns between the application of 8 and the 4 wave conditions. The statistical parameters also indicated that this difference is minimal (i.e., RMS error $\sim 0004$ and $\mathrm{R}^{2} \sim 0.0012$ ). Considering these results and the fact that each wave condition should be 
applied in a complete tidal cycle (see Dissanayake 2011), the last four wave conditions are selected to hindcast the bed evolution in the Ley Bay area.

a. Wave climate

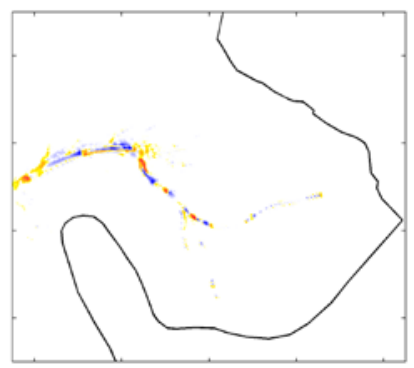

b. 8 wave conditions

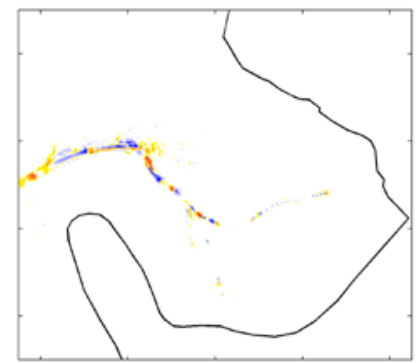

c. 4 wave conditions

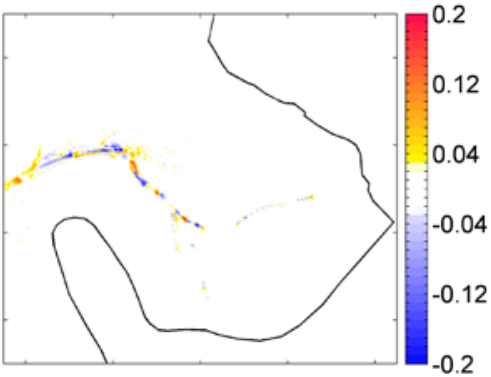

Figure 4. Erosion/Sedimentation pattern in the Ley Bay area in short-term (two-week morphological period) simulations applying the wave climate (a), last 8 wave conditions (b) and last 4 wave conditions (c).

Once four wave conditions are selected out of 73 conditions (i.e., wave climate), the respective wind characteristics can also be found from the wind-speed and wind-direction scatter diagrams. Table 1 shows the selected four wave conditions and their corresponding weight factors together with the wind conditions. It is emphasized that the weight factor does not necessarily represent the dominant wave direction. In the study area, the dominant wave condition is from NW direction. It is proven with the selected four conditions also (see $\mathrm{H}_{\mathrm{s}}=3.4 \mathrm{~m}$ and $1.4 \mathrm{~m}$ are from $\mathrm{NW}$ ). Table 1 indicates, the highest weight factor is assigned to the lowest wave height and vice versa. Therefore, the contribution of lower wave heights (i.e., calm period) appears to be considerable than that of the higher wave heights (i.e., extreme conditions) on the long-term bed level changes. This further agrees with the criterion 1 of our wave schematization.

\begin{tabular}{|c|c|c|c|c|c|c|}
\hline \multicolumn{4}{|c|}{ Wave Characteristics } & \multicolumn{2}{|c|}{ Wind } & \multirow{2}{*}{ Weight factor } \\
\hline No & $\begin{array}{l}\mathrm{Hs} \\
(\mathrm{m})\end{array}$ & $\begin{array}{l}\mathrm{Tp} \\
\text { (s) }\end{array}$ & $\begin{array}{c}\text { Dir. } \\
\text { (deg. Nau.) }\end{array}$ & $\begin{array}{c}\text { Speed } \\
(\mathrm{m} / \mathrm{s})\end{array}$ & $\begin{array}{c}\text { Dir. } \\
\text { (deg. Nau.) }\end{array}$ & \\
\hline $\mathrm{H} 1$ & 0.4 & 3.9 & 90 & 6.8 & 108 & 0.45 \\
\hline $\mathrm{H} 2$ & 1.4 & 5.3 & 271 & 10.2 & 219 & 0.26 \\
\hline H3 & 3.4 & 9.0 & 330 & 12.9 & 293 & 0.11 \\
\hline $\mathrm{H} 4$ & 1.4 & 6.8 & 331 & 6.9 & 270 & 0.12 \\
\hline
\end{tabular}

\section{Model runs}

Initially, two hydrodynamic simulations were undertaken applying the 1975 and 1990 bathymetries respectively to compare and contrast the effect of the peninsula in the Ley Bay hydrodynamic pattern. In both simulation stages (i.e., from 1975 to 1984 and from 1984 to 1990), it is required to apply the wave conditions systematically rather than in four periods of the simulation duration in order to sufficiently represent the natural variability. Wave chronology affects the bed evolution (see Dissanayake 2011). However, a single chronology was employed in this study as was derived from the wave schematization (see Table 1). A single MORFAC value was adopted for all wave conditions while the contribution of each wave condition is represented by their different hydrodynamic periods which are proportional to their weight factors. Such approach helps to avoid mass conservation problems due to different MORFAC values during a single model run.

The first stage of the simulation spans for 9 years. A hydrodynamic period of 35 days was selected enclosing two cycles of spring-neap-spring. Within this period, a small hydrodynamic unit of 5 days was defined such that it is possible to apply all four wave conditions along complete tidal cycles and corresponding to their specific weight factors (see Table 2). This 5-day combination is then repeatedly applied throughout the model duration. Resulting MORFAC value is about twice than the case of tidal 
boundary only (see Dissanayake et al. 2012a) and therefore the initially selected hydrodynamic period was doubled. The MORFAC value is given by,

MORFAC $=\frac{\text { morphological period }}{\text { hydrodynamic period }}=\frac{9 \times 365}{(35 \times 2)} \sim 46$

Accordingly, each wave condition is responsible for a specific morphological period with a unique MORFAC value along the complete simulation period. Table 2 summarises application of wave conditions and their corresponding hydrodynamic and morphological periods. Selected wind conditions were also applied together with the corresponding wave conditions.

\begin{tabular}{|c|c|c|c|}
\hline \multicolumn{4}{|c|}{ Table 2. Application of wave conditions along the simulation period. } \\
\hline No & Weight factor & $\begin{array}{c}\text { Tidal cycles within } \\
\text { a 5-day unit }\end{array}$ & Morphological period (years) \\
\hline H1 & 0.5 & 5 & 4.5 \\
H2 & 0.3 & 3 & 2.7 \\
H3 & 0.1 & 1 & 0.9 \\
H4 & 0.1 & 1 & 0.9 \\
\hline
\end{tabular}

In the second stage (i.e., 6-year period from 1984 to 1990), the initial bathymetry was adopted as the final predicted bathymetry of the previous stage. The Leyhörn peninsula was implemented on this bathymetry. It is noted that there are only 1975 and 1990 measured bathymetries within the study period and therefore it is unavoidable applying the peninsula information from the 1990 bed. This stage also used the previous MORFAC value with an adjusted hydrodynamic period to investigate the 6-year evolution.

\section{RESULTS}

\section{Hydrodynamics}

Maximum tidal flow is expected in the basin/inlet systems during mid-tidal water levels (see Dissanayake et al. 2009). Therefore, the tidal flow pattern at mid-flood was analysed before (bluevectors) and after (red-vectors) implementing the Leyhörn peninsula to compare and contrast the effects (Fig. 5). Both patterns suggest extensive tidal flats and salt marshes in the Ley Bay and provide first insight of the impact of Leyhörn on the existing flow pattern. At the west of the peninsula (north is up), the tidal flow shows a weaker velocity pattern after implementing the peninsula. This indicates that the peninsula interrupts the velocity vectors which are directed into the Ley Bay prior to the peninsula. At the north of the peninsula, the flow vectors are larger than the pre-peninsula state, implying that the peninsula triggers stronger tidal currents due to the flow contraction. In the Ley Bay area, the tidal currents tend to orient more eastward and also being stronger with the peninsula. This phenomenon is evident by comparing the flow pattern in the channels (i.e., Leysander Priel, Greetsieler Watt. and Norder Außentief, see Fig. 2a for channel locations) under both situations. 


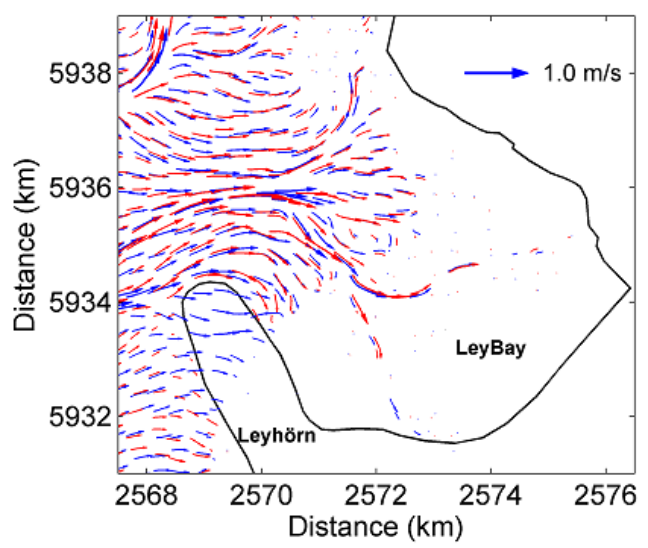

Figure 5. Effect of Leyhörn peninsula in the Ley Bay flow pattern referring to tidal currents at mid-flood water level, before (blue) and after (red) implementing the peninsula.

\section{Bed evolution}

Fig. 6 shows the 1990 modeled bed in comparison to the measured beds in 1975 and 1990. The major difference between 1975 and 1990 bathymetries is the presence of the Leyhörn peninsula on the 1990 bed. In the study period, the Ley Bay evolution mainly indicates three differences,

- $\quad$ Strong sedimentation in the Ley Bay

Moving shallow contour lines towards the channel boundaries and the middle of the bay is evidence of strong sedimentation due to the peninsula construction.

- $\quad$ Silting-up of the southward channel in the bay (i.e., Greetsieler Wattfahrwasser, see Fig 2a)

The 1990 bed shows that the southward channel has positive depth values in contrast to that of the negative values on the 1975 bed (refer the colour palette). This suggests silting-up of this channel because of the peninsula.

- $\quad$ Pronounced-configuration of the eastward oriented channel (i.e., Norder Außentief, see Fig 2a)

Fig. 5 shows increase of eastward oriented flow pattern in the bay after implementing the peninsula. Such phenomenon is attributed to develop the pronounced channel configuration as found on the 1990 bed.

By comparing these differences with the modeled bed, it is able to estimate the predictability of the model approach. On the model predicted bed, the shallow areas appear to have squeezed rather than expanded in contrast to the 1990 measured bed. This seems to be governed by the highly schematised wave climate which includes one rather extreme event $\left(\mathrm{H}_{\mathrm{s}}=3.4 \mathrm{~m}\right)$. In generally, strong sedimentation is only found in the channel areas. Silting-up of the southward channel is sufficiently represented by the model (refer to colour change in $a$ and $c$ ). Eastward orientation of the bay channel pattern is also clearly found on the model prediction as similar to the measured bed.
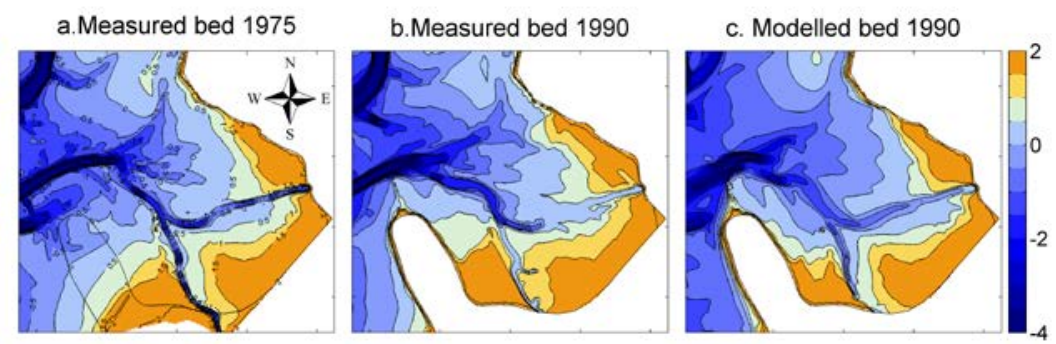

Figure 6. Comparison of measured and model predicted bathymetries in the Ley Bay, Measured bed 1975 (a), Measured bed 1990 (b) and Modelled bed 1990 (c).

\section{Cross-sectional evolution}

Predicted bed evolution indicated a general agreement with the measured data. Furthermore, channel areas agree better than inter-tidal areas. Therefore, evolution of the channel areas is further compared in terms of their cross-sections. Selected cross-sections in this analysis $A, B, C$ and $D$ are given in Fig.1. Cross-section $A$ is located in front of the bay entrance while the other three are located inside the bay. 
Fig. 7 shows the selected cross-sections of the measured data and the model prediction ( $x-$ axis is horizontal distance $(\mathrm{km})$ and $y$ - axis is water depth $(\mathrm{m}))$. It is apparent that $A$ is located in the deepest channel while $C$ and $D$ are found in the shallowest channels in the bay area. All cross-sections show strong sedimentation from 1975 to 1990 evolution (see dash-line and black-line). At $A$, the channel depth decreases about $3 \mathrm{~m}$ during this period. It is remarkable that the model also indicates such a strong decrease in depth though the modeled right-bank is relatively deeper than the data. On the 1975 bed, cross-section $B$ is narrow and deeper. This has become wider and shallow $(\sim 2 \mathrm{~m})$ on the 1990 bed. The model prediction shows fairly good agreement with the data. However, there is a marginal shift between data and the model results. Such difference is assumed a result of dredged material disposal on the left-bank area during the peninsula construction. At $C$, channel depth decreases up to about $1.5 \mathrm{~m}$ in nature. This is shown by the model prediction as well. However, it is generally found that this area receives less amount of sediment compared to the data. Section $C$ also consists of a marginal shift as found in the $B$. Section $D$ is located at a distal part of the eastward oriented bay channel and its depth decreases up to about $1.5 \mathrm{~m}$ during the evolution. The model prediction is also fairly consistent with the data. In contrast to the previous channel section, this area has received sufficient amount of sediment though the spatial distribution differs from the data.

A
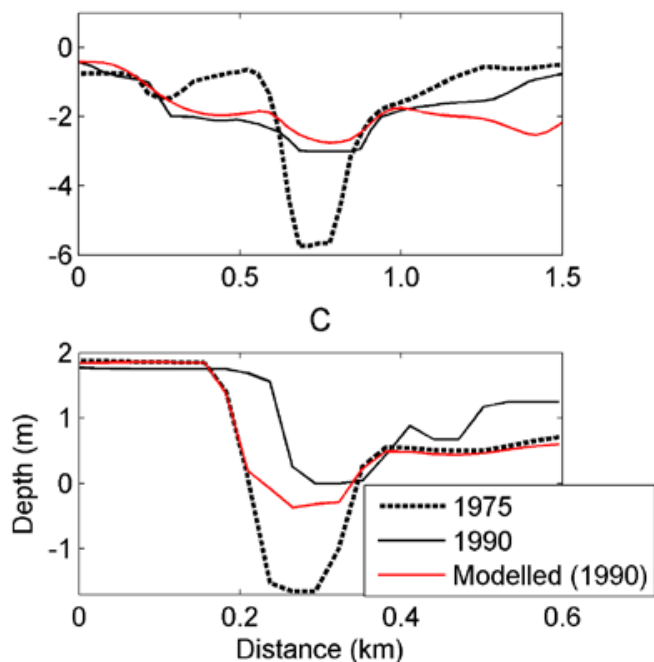

B
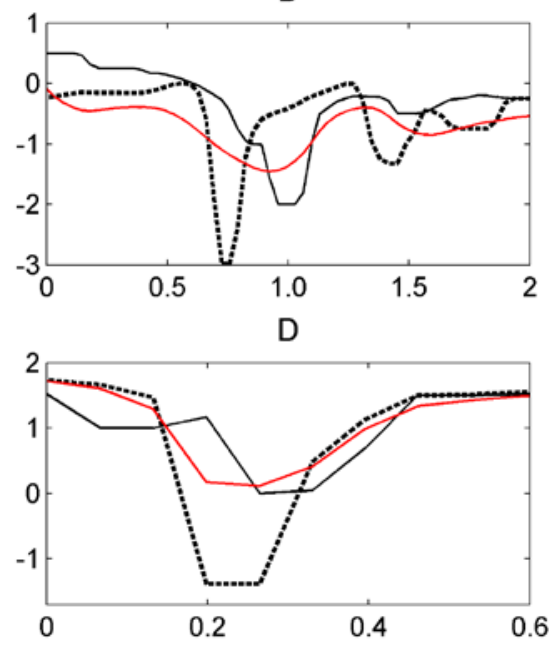

Figure 7. Evolution of channel cross-sections in measured data and model prediction; 1975 data (dash-line), 1990 data (black-line) and model prediction (red-line), cross-section locations are referred to Fig. 1.

\section{Erosion and Sedimentation}

It provides more insight of the model prediction by comparing the spatial extent of bed level changes during the study period. Fig. 8 shows the areas where erosion and sedimentation occurred in the measured data and the model predicted bed. In the Ley Bay, the channel sedimentation is well reproduced by the model though the predicted areas are not as strong as in the data. Furthermore, the main channel leading into the Ley Bay (i.e., Norderley, see Fig. 2a) also indicates similar pattern of sedimentation in both cases. There is sedimentation at inter-tidal areas close to the channels on the measured bed. Such areas are not found on the model prediction. This is mainly assumed due to maintenance dredging undertaken in these two channels prior to construction of the peninsula and dumping of the dredged material on adjacent inter-tidal areas. Southward channel was continuously dredged to facilitate access to the nearby fishing harbor (i.e., Greetsieler Harbour, see Fig. 1). Eastward channel was mainly dredged to maintain inland drainage in term of water level controlled gate outlets. These dredging activities were not incorporated in the present model due to lack of specific data. Erosion area around the peninsula expands more in the case of data than in the model prediction. One can expect dumping of sediment in this area due to deepening of the area inside the peninsula (Note: in Fig. 2a, the area enclosed by the peninsula is very shallow on the 1975 bed and therefore it is necessary to deepen in order to facilitate navigation through the peninsula). This also was not taken into account in this study because no detailed data is available. Erosion areas (refer blue-patches in Fig. 8) are generally found along the channels. Away from the peninsula, these areas appear to have reproduced by 
the model (see area to the north of the peninsula). However, they weakly agree to the east of the peninsula. As found in the cross-sectional evolution (see Fig. 7), the data indicates an eastward shift of the main basin channel (i.e., Leysander Priel, see Fig. 2). This further attributes to the fact that dumping of sediment adjacent to the peninsula during its construction. Referring to the channel at the NW end of Fig. 8, the measured data consists of erosion areas whereas the model results indicate strong sedimentation. The latter is assumed an effect of the highly schematised wave climate with an extreme event which results in stronger influence of the hydrodynamic boundary conditions at the east and the west sides of the computational domain leading to stronger sediment transport patterns. These results suggest the application of different schematization procedures of the wave climate and to investigate their sensitivity on the bed evolution.
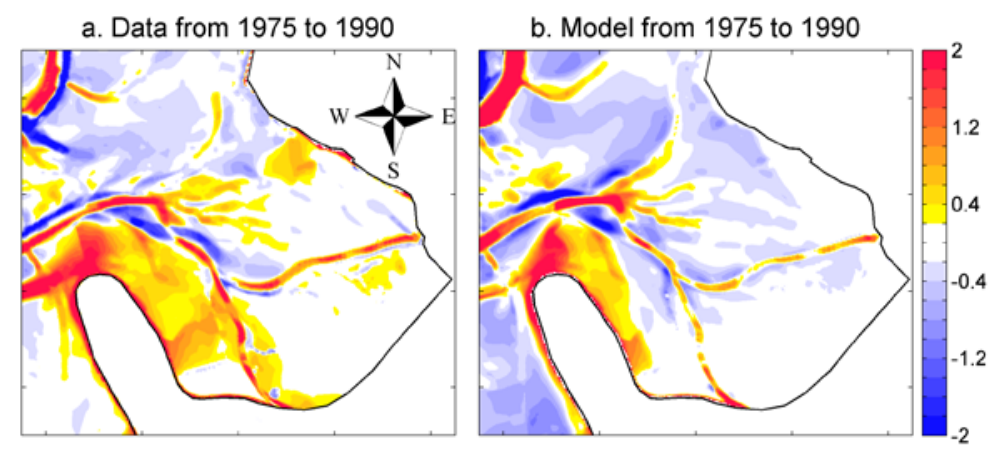

Figure 8. From 1975 to 1990 erosion and sedimentation pattern in the Ley Bay area based on measured data (a) and model prediction (b).

The erosion/sedimentation pattern is further analysed in terms of the overall sediment volume change in the Ley Bay only during the morphological period. As mentioned earlier, this study is based on two measured bathymetries (i.e., 1975 and 1990). Therefore, the model predicted temporal evolution of the volume change is compared with the volume change between the two available measured bathymetries (see Fig. 9). In the first stage from 1975 to 1984, resulting evolution indicates increase in sedimentation as well as erosion. However, the rate of increase in erosion is higher than that of the sedimentation, what overall results in net sediment export from the bay. This tends to contradict with what has been observed in nature. Prior to construction of the peninsula, there were sedimentation problems in the bay channels. The latter observation was sufficiently reproduced by the model (see Fig. 8) whereas dumping on the inter-tidal areas and channel banks adds more resistance to erosion. Unless these man-made interventions are implemented in the model, those areas are prone to erosion. As such, the model results imply a sediment exporting system. In the second stage, the peninsula was introduced on the 1984 predicted bathymetry. Therefore, temporal evolution of sedimentation and erosion shows discontinuities. The step at sedimentation is relatively higher than that at erosion. This is expected after applying the dyke of the peninsula and removing the area enclosed by the peninsula from the model domain. Evolution in this stage indicates marginal change in erosion and sedimentation. It is noted that the amount of erosion is still higher than the sedimentation and therefore again implies a sediment exporting system. However, this observation agrees with the reality in which the Ley Bay tends to turn into an exporting system after implementation of the peninsula. On the 1990 bathymetry, both predicted sedimentation and erosion volumes are lower than those of the measured data. As mentioned earlier, the area inside the peninsula has been deepened to facilitate navigational access. It is expected that the dredged material in this process was dumped in the adjacent Ley Bay area. If this additional sediment amount was not included on the 1984 initial bed, resulting evolution would indicate in lower volume changes in both sedimentation and erosion as in Fig. 9. Therefore, more reasonable bed evolution can be expected only after implementing dredging and dumping activities undertaken in this area. 


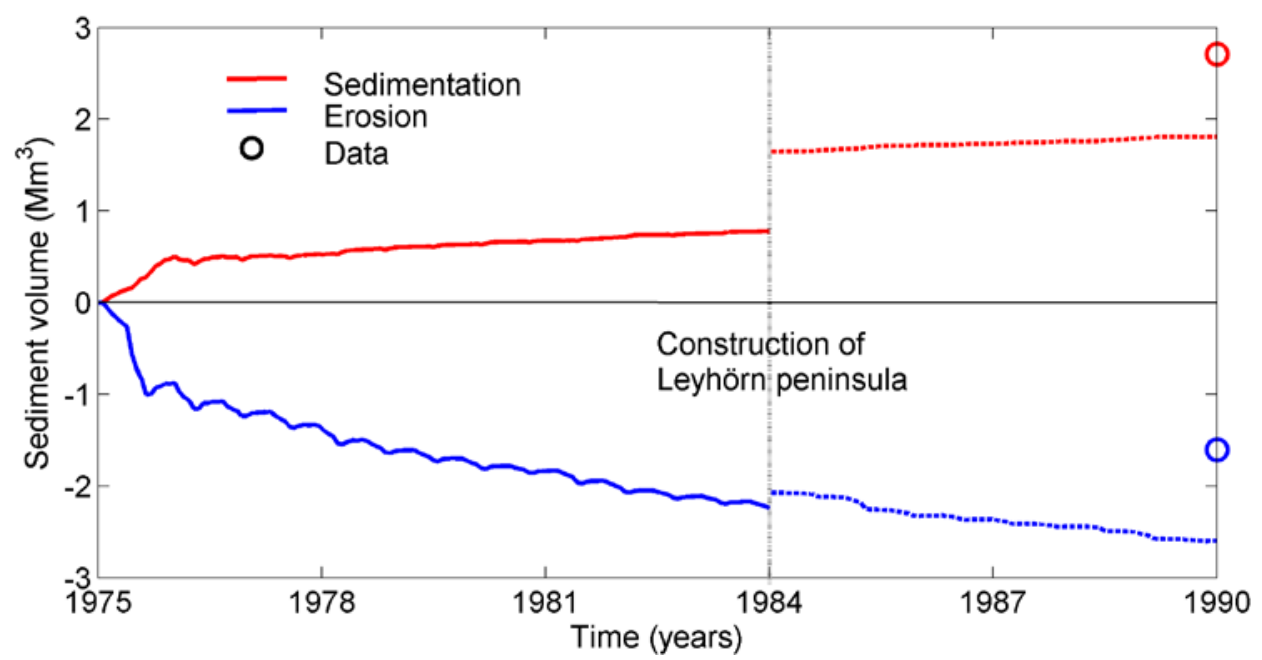

Figure 9. Model predicted temporal evolution of the erosion and sedimentation volume inside the Ley Bay area with the measured data.

In the previous analyses, the comparison between predicted and measured data was mainly undertaken in a qualitative sense. Next, a statistical analysis is used to determine the model skill in which the predicted bed can be classified into different states.

\section{Statistical analysis}

Brier Skill Score (BSS) (Sutherland et al. 2004) was adopted to quantitatively determine whether the predicted bed gives a better representation of the 1990 measured bathymetry. It is noted that the BSS is not a perfect method to evaluate model performance especially where individual characteristics such as basin infilling, lateral displacement and rate of bifurcation of channels etc. are concerned. However, at present, this is the most widely adopted method to objectively assess the model skill (Dissanayake et al. 2012a,b; Roelvink et al. 2009; Ruggiero et al. 2009), and due to the lack of a better alternative, the BSS approach is used here to evaluate the model skill. The BSS is defined by Sutherland et al (2004) as,

$B S S=\frac{\alpha-\beta-\gamma+\varepsilon}{1+\varepsilon}$

where, $\alpha=r_{Y^{\prime} X^{\prime}}^{2} \beta=\left(r_{Y^{\prime} X^{\prime}}-\frac{\sigma_{Y^{\prime}}}{\sigma_{X^{\prime}}}\right)^{2} \gamma=\left(\frac{\left\langle Y^{\prime}\right\rangle-\left\langle X^{\prime}\right\rangle}{\sigma_{X^{\prime}}}\right)^{2} \varepsilon=\left(\frac{\left\langle X^{\prime}\right\rangle}{\sigma_{X^{\prime}}}\right)^{2}$

and $X^{\prime}=Z_{1990}-z_{1975}, Y^{\prime}=Z_{\text {model }}-Z_{1975}$

$z$, bed levels in $1975\left(z_{1975}\right), 1990\left(z_{1990}\right)$ and model $\left(z_{\text {model }}\right)$ beds $\alpha$, a measure of bed form phase error and perfect model gives $\alpha=1$

$\beta$, a measure of bed form amplitude error and perfect model gives $\beta=0$

$\gamma$, an average bed level error and perfect model gives $\gamma=0$

$\varepsilon$, a normalization term which indicates the measurement error

In the above definition of the BSS, a value of 1 indicates an excellent comparison between the measurements and the model results. Negative BSS values imply large differences of modelled and measured bathymetries. Sutherland et al (2004) give the following classifications for the assessment of model performance against the BSS (see Table 3). 


\begin{tabular}{|l|c|}
\hline \multicolumn{2}{|c|}{ Table 3. Classification of BSS values by Sutherland et al (2004). } \\
\hline \multicolumn{1}{|c|}{ Classification } & BSS \\
\hline Excellent & $1.0-0.5$ \\
Good & $0.5-0.2$ \\
Reasonable/Fair & $0.2-0.1$ \\
Poor & $0.1-0.0$ \\
Bad & $<0.0$ \\
\hline
\end{tabular}

The BSS analysis was undertaken only for the second stage of evolution (i.e., 1984 to 1990) because it is not realistic to compare the pre-peninsula bathymetry (prior to 1984) with the 1990 measured bed. During this morphological period, the overall change of these parameters $(\alpha, \beta, \gamma$ and $\varepsilon)$ is marginal implying that a large part of the Ley Bay area remains unchanged (see Fig. 8 also). The phase error $(\alpha)$ which indicates position of bed forms varies around 0.35 . Magnitude of bed forms is given by amplitude error $(\beta)$ and it increases up to about 0.05 . The average bed level error $(\gamma)$ remains around 0.2 . The estimated measurement error $(\varepsilon)$ based on the 1975 and 1990 measured beds is constant $(0.1)$ throughout the period. On the 1990 predicted bed, these values resulted in a BSS of 0.16. Following Table 3, the BSS value qualifies the model prediction as 'Reasonable/Fair'.

\section{CONCLUSIONS}

A numerical approach was undertaken to investigate an anthropogenic effect on a tidal basin evolution. Study area is based on the Ley Bay which is located in the East Frisian Wadden Sea. A peninsula has been constructed in the Ley Bay in 1984 to mitigate numerous coastal management issues (e.g., coastal flooding, navigational access, inland drainage etc.). A coupled numerical model was used to hindcast the bed evolution from 1975 to 1990 applying both tidal and wave boundary forcings with a multiple sediment bed (see Dissanayake et al. 2012a). The offshore tidal forcing was transformed to the study area by means of a model cascade approach consisting of two nested models, 1) From Continental shelf model to Coastal model and 2) From Coastal model to Study area. A highly schematised wave climate with only four wave conditions was employed in this simulation. The schematization procedure is based on the probability of occurrence and the relative contribution of each wave condition to the overall bed level change of the wave climate.

Two complete bathymetries (i.e., 1975 and 1990) were available in this study. Therefore, the peninsula construction was implemented on the 1984 predicted bed based on the 1990 peninsula configuration. Resulting evolution indicates that the deeper areas are well reproduced by the model rather than the shallow areas. Therefore, channel evolution has a good agreement with the data compared to the tidal flat areas (Note: a large part of the Ley Bay consists of inter-tidal and supra-tidal areas). In addition to the peninsula construction, the human interference in terms of dredging and dumping has partly influenced on the Ley Bay evolution. Prior to the peninsula, the bay channels have been continuously dredged to maintain navigational access and inland drainage. The dredged material is expected to have dumped on the inter-tidal or supra-tidal areas (see Fig. 8a). During the peninsula construction (constructing outer dyke and deepening inside the peninsula), further sand disposal is assumed to have undertaken in the Ley Bay area. Due to the lack of data availability, this information cannot be incorporated. However, qualitative and quantitative analyses show that the predicted bathymetry sufficiently resembles the measured data.

Applying a highly schematised wave climate dominates the bed evolution. Further investigation on wave schematization is carried out in order to optimize the model prediction. The presented work is currently continued to forecast the Ley Bay evolution under future sea level rise scenarios.

\section{ACKNOWLEDGMENTS}

The work presented in this paper was carried out under the project of 'Veränderliches Küstenklima Evaluierung von Anpassungsstrategien im Küstenschutz (A-KÜST: Changing Coastal Climate Evaluation of Adaption Strategies for Coastal Protection)' as a part of 'Klimafolgenforschung Szenarien für die Klimaanpassung' (KLIFF: Climate Impact Research for Adaption)' funded by the Lower Saxon State Ministry for Science and Culture, Germany. 


\section{REFERENCES}

Dissanayake, D.M.P.K. 2011. Modelling morphological response of large tidal inlet systems to sea level rise, CRC Press, Taylor \& Francis Group, ISBN 978-0-415-62100-7.

Dissanayake, D.M.P.K., R. Ranasinghe, J.A. Roelvink. 2012b. The morphological response of large tidal inlet/basin systems to Relative Sea Level Rise. Climatic Change, DOI: 10.1007/s10584-0120402-z

Dissanayake, D.M.P.K., J.A. Roelvink, M. Van der Wegen. 2009. Modelled channel pattern in schematised tidal inlet. Coastal Engineering 56, 1069 - 1083.

Dissanayake, D.M.P.K., A. Wurpts, M. Miani, H. Knaack, H.D. Niemeyer, J.A. Roelvink.2012a. Modelling morphodynamic response of a tidal basin to an anthropogenic effect: Ley Bay, East Frisian Wadden Sea - applying tidal boundary only and different sediment fractions Coastal Engineering, 67, 14 - 28.

Elias, E., M.J.F. Stive, J.G. Bonekamp, J. Cleveringa. 2003. Tidal inlet dynamics in response to human intervention, Coastal Engineering 45(4), 629-658.

Hartung, W. 1983. Die Leybucht (Ostfriesland) - Probleme ihrer Erhaltung als Naturschutzgebiet, Neues Archiv f. Niedersachsen, Bd. 32, H. 4, Göttingen, S. 355-387.

Homeier, H., H.J. Stephan, H.D. Niemeyer. 2010. Historisches Kartenwerk Niedersächsische Küste der Forschungsstelle Küste, Niedersächsischer Landesbetrieb für Wasserwirtschaft, Küsten- und Naturschutz (NLWKN), Geschäftsbereich Gewässerbewirtschaftung und Flussgebietsmanagement.

Knaack, H., R. Kaiser, H.D. Niemeyer. 2003. Mathematische Modellierung von Tiden in der Leybucht, Dienstbericht, Niedersächsisches Landesamt für Ökologie, Forschungsstelle Küste, Norderney (in Deutsch).

Knaack, H., H.D. Niemeyer. 2001. Morphodynamische Gleichgewichtszustände in der Leybucht zwischen 1960 und 1999, Dienstbericht, Niedersächsisches Landesamt für Ökologie, Forschungsstelle Küste, Norderney (in Deutsch).

Lesser, G.R., J.A. Roelvink, J.A.T.M. Van Kester, G.S. Stelling. 2004. Development and validation of a three-dimensional morphological model, Coastal Engineering 51, 883-915.

Niemeyer, H.D. 1984. Hydrographische Untersuchungen in der Leybucht zum Bauvorhaben Leyhörn, Jahresbericht 1983 Forschungsstelle f. Insel- u. Küstenschutz, Bd. 35, Norderney, S. 61-98 (in Deutsch).

Roelvink, D., A. Reniers, A.Van Dongeren, J.V.T. De Vries, R. McCall, J. Lescinski. 2009. Modelling storm impacts on beaches, dunes and barrier islands, Coastal Engineering 56, 1133-1156.

Ruggiero, P., D.J.R. Walstra, G. Gelfenbaum, M. Van Ormondt. 2009. Seasonal-scale nearshore morphological evolution: Field observations and numerical modelling, Coastal Engineering 56, 1153-1172.

Sutherland, J., A.H. Peet, R.L. Soulsby. 2004. Evaluating the performance of morphological models, Costal Engineering 51, 917-939.

Thijsse, J.T. 1972. Een halve Zuider Zeewerken 1920-1970, Tjeenk Willink, Groningen.

Verboom, G.K., J.G. De Ronde, R.P. Van Dijk. 1992. A Fine Grid Tidal Flow and Storm Surge Model of the North Sea, Continental Shelf Research, Vol. 12. 